\title{
Cervical Sagittal Alignment Parameters-What do we Know So Far? A Mini-Review
}

\author{
Vibhu Krishnan Viswanathan* and Surabhi Subramanian \\ The Ohio State University, USA
}

Received: April 23, 2018; Published: June 11, 2018

*Corresponding author: Vibhu Krishnan Viswanathan, Clinical Spine Fellow, The Ohio State University, USA, Tel: +16143023859;

Email: drvibu007@gmail.com

\section{Introduction}

Being the most mobile segment of spine, cervical spine tends to reciprocally align itself in both sagittal and coronal planes in response to any alteration in the contour throughout the reminder of vertebral column [1]. Similarly, alterations in the cervical spinal alignment are also compensated by other spinal segments in order to maintain horizontal gaze. With recent advances in the concepts of spinal instrumentation, Neuromonitoring abilities and deformity correction surgeries, the need for understanding the intricacies of cervical deformity is well-acknowledged [2]. Multiple radiological cervical alignment parameters have thus far, been described; and a complete understanding of these parameters is necessary to understand the concept of cervical deformity surgeries.
Cervical Sagittal Alignment-Radiological Parameters

\section{Cervical lordosis}

The initial papers on the dynamic behaviour of cervical spine were described in 1950's and different techniques of calculating cervical spinal lordosis have been discussed since then $[3,4]$ Figure 1. Weir et al. [5] observed the incidence of straightening or inversion of cervical lordosis in asymptomatic population to be around $20 \%$. The different ways of measuring CL include Cobb method, Jackson physiological stress lines, Harrison's posterior tangent method and Ishihara index [6-8]. Using the Cobb method, the angle subtended by the perpendicular drawn to lines along the inferior end plate of $\mathrm{C} 2$ or tangential to $\mathrm{C} 1$ anterior and posterior tubercles; and the inferior end plate of C7 defines CL.

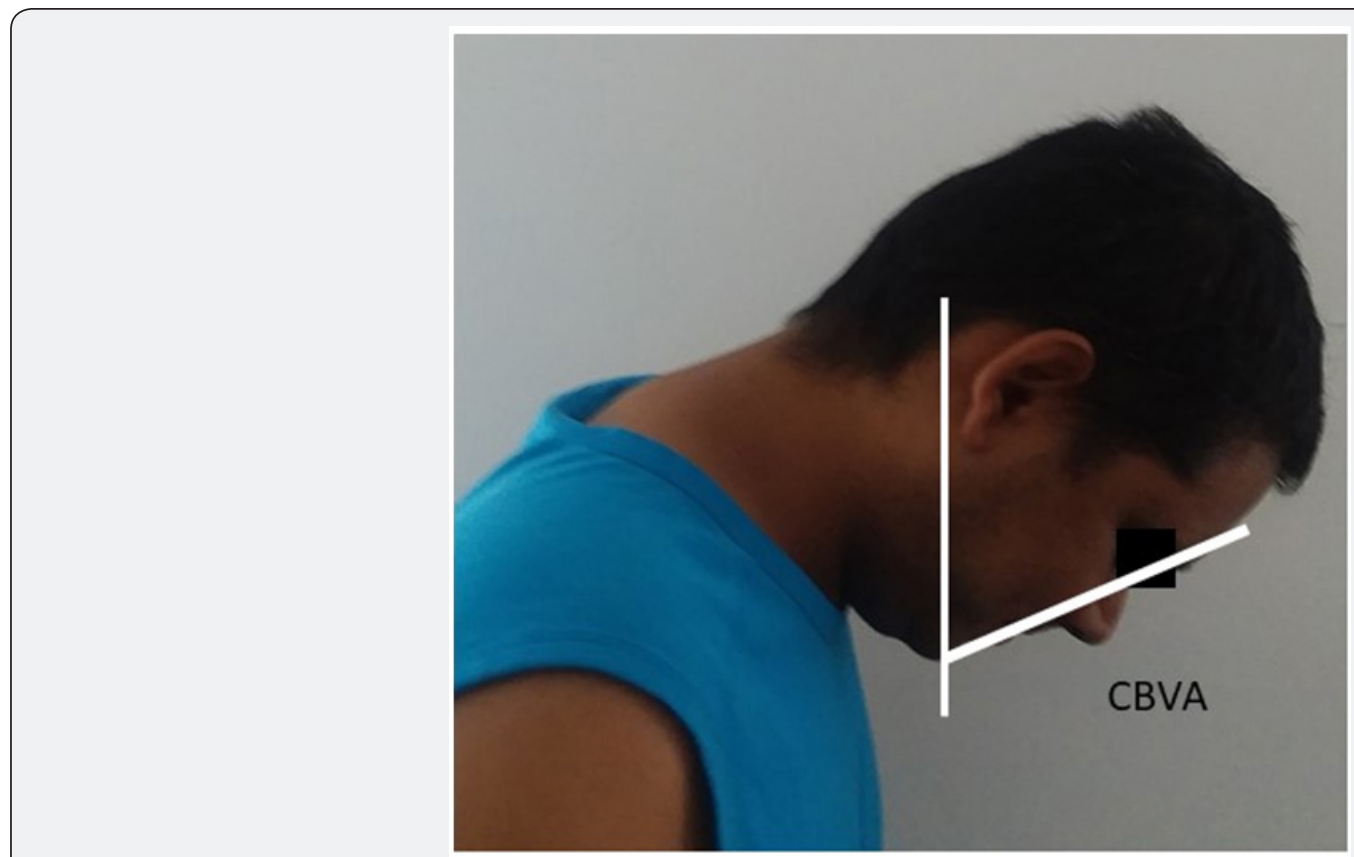

Figure 1: Sagittal image of cervical spine depicting A. Cervical lordosis-angle subtended by the perpendicular drawn to lines along the inferior end plate of $\mathrm{C} 2$ or tangential to $\mathrm{C} 1$ anterior and posterior tubercles; and the inferior end plate of C7 (Cobb's method) and C0-C2 lordosis-angle subtended by the perpendicular drawn to lines along the inferior end plate of C2 and the McGregor's line (Cobb's method). 
Jackson physiological stress technique defines CL as the angle between the lines along the posterior vertebral walls of $\mathrm{C} 2$ and C7. Harrison's posterior tangent techniques describes CL as the sum of all segmental cervical curvature angles obtained by drawing tangents along the posterior vertebral walls of $\mathrm{C} 2-\mathrm{C} 7$ vertebrae. Ishihara cervical curvature index defines the ratio of the sum of horizontal lines drawn between vertical line between $\mathrm{C} 2$ and $\mathrm{C} 7$ and the postero-inferior edges of C3, C4, C5, C6; and the vertical between poster-inferior edges of $\mathrm{C} 2$ and $\mathrm{C} 7$. A higher Ishihara index indicates lordosis, while lower index indicates kyphosis and "zero" index indicates a straight spine. Although all these described techniques of CL measurement have good intraand inter-observer reliabilities, Cobb's method has been shown to underestimate CL.

CL increases with age [8]. While $77 \%$ of CL happens at C1-2 level, the remaining $23 \%$ is contributed by the remaining sub-axial cervical spine [9]. While the mean C0-C2 lordosis is reported to be $22.4 \pm 8.5$, the mean contribution at sub-axial spine (C2-C7) is $9.9 \pm 12.5$ [10].

\section{C2-C7 Sagittal vertical axis}

C2-C7 SVA or sagittal vertical axis deviation is the distance between the $\mathrm{C} 2$ plumb line and the poster superior end plate of C7 vertebra Figure 2. Theoretically, an increase in the C2-C7 SVA indicates an increase in the flexion moment of the cervical spine and a consequent increase in the energy expenditure of the posterior cervical spinal musculature in order to maintain an erect posture. The mean SVA on erect radiographs in asymptomatic individuals has been has been reported around 21.3mm [11]. The correlation between C2-C7 SVA and disability is relatively weak, nevertheless there is evidence (albeit not very clear) that C2-C7 SVA more than $40 \mathrm{~mm}$ is associated with significant disability. This is currently a measure of great interest in cervical deformity and further research can help us obtain a definitive knowledge on the exact usefulness of this parameter [9].

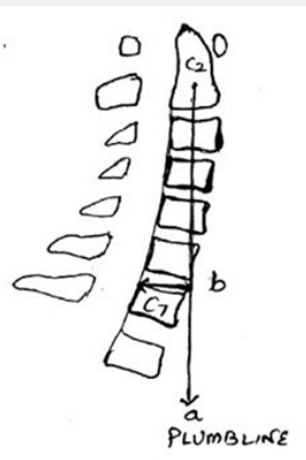

Figure 2: C2-C7 SVA or sagittal vertical axis deviation-Distance between the $\mathrm{C} 2$ plumb line and the posterosuperior end plate of C7 vertebra.

\section{Chin brow vertical angle}

Figure 3 Chin Brow Vertical Angle (CBVA) is another indirect measurement of cervical sagittal alignment, measured either with clinical photographs or whole spine radiographs with the patient standing upright, neutral neck and extended hips and knees [9]. It is the angle between the line joining chin and brow and the vertical. When the head is tilted down, CBVA is positive; and when the head is tilted up, CBVA is negative. In a prospective study reported by Suk et al. [12,13] CBVA ranging between $-10^{\circ}$ and $+10^{\circ}$ is recommended for optimal horizontal gaze following kyphosis correction surgery in ankylosing spondylitis.

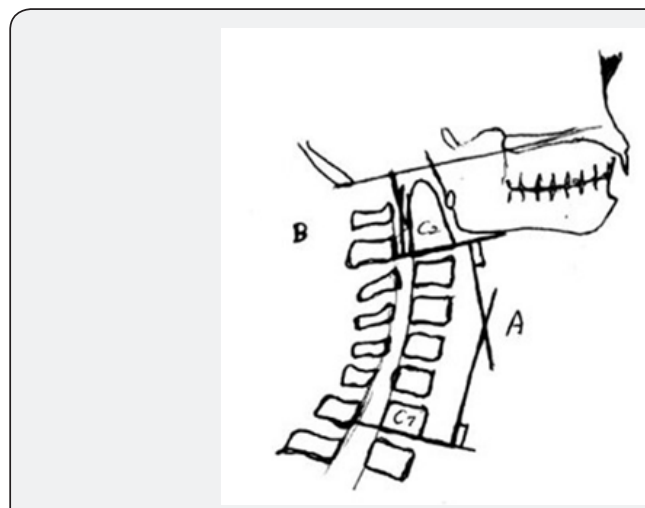

Figure 3: Chin Brow Vertical Angle-Angle between the line joining chin and brow and the vertical.

\section{T1 slope, neck tilt angle and thoracic inlet angle}

Figure 4 Attempts to bring out radiological parameters analogous to pelvic parameters have resulted in the description of T1 slope (T1S), Neck tilt angle (NTA) and Thoracic Inlet angle (TIA). TIA was described by Lee at al. [14] as the angle subtended by the line connecting the upper end of sternum and middle of T1 upper endplate and line perpendicular to upper end plate of T1. Although this can be measured on lateral radiographs, Computerized Tomography (CT) and Magnetic Resonance Imaging (MRI) provide better visualization of these salient radiographs landmarks [14]. This was described as an equivalent of pelvic incidence (PI).

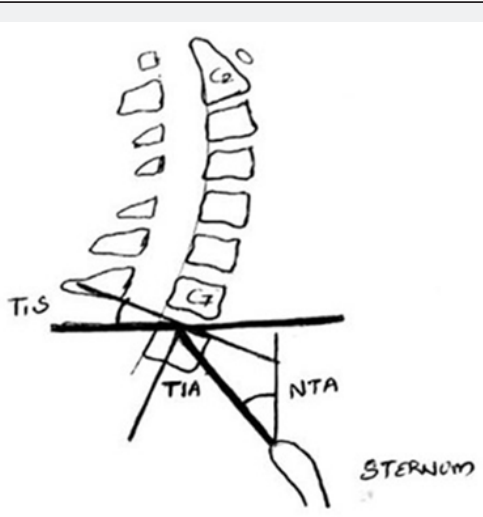

Figure 4: Sagittal image of cervical spine depicting T1 slope (T1S)-Angle between the superior endplate of $\mathrm{T} 1$ and the horizontal, Neck tilt angle (NTA)-Angle between line connecting sternum and middle of T1 upper end plate and the vertical axis; and Thoracic Inlet angle-angle subtended by the line connecting the upper end of sternum and middle of T1 upper endplate and line perpendicular to upper end plate of $\mathrm{T} 1$. 
It was initially described as a fixed morphological angle [14], although further reports demonstrated a change in this parameter with alterations in the position of neck (flexion versus neutral versus extension) [15]. T1S is the angle between the superior endplate of T1 and the horizontal and has been considered analogous to sacral slope (SS) [9]. T1S angle of more than $40^{\circ}$ has been demonstrated to be associated with poor health-related quality of life (HRQOL). Similarly, T1S more than $25^{\circ}$ has been shown to correlate with overall sagittal imbalance (C2-S1 SVA more than $10 \mathrm{~cm})$.

The difference between T1S and CL has been a parameter of growing interest recently. T1S-CL more than $20^{\circ}$ has been significantly correlated with poor HRQOL $[16,17]$. Hyun et al. [18] described the relationship between T1S, CL and CSVA. In their study, T1S-CL of more than $26.1^{\circ}$ corresponds to C2-C7 SVA of more than $50 \mathrm{~mm}$. NTA, which has been described analogous to pelvic tilt (PT) is defined as the angle between line connecting sternum and middle of $\mathrm{T} 1$ upper end plate and the vertical axis. There has been a recommendation that patients with NTA outside the range of $13^{\circ}$ and $25^{\circ}$ need to undergo 36-inch whole spine radiographs [15].

These three parameters are of growing interest to researchers; and are considered to reflect the interactions between cervical alignment and deformities of the rest of spine/ body or thoracic cage. The exact utility of these parameters is still far from lucid; and their role in surgical planning is a topic for future research.

\section{Cervical deformity classification}

Table 1 owing to the relative rarity of cervical deformities, there is currently no universally accepted classification system similar to thoracolumbar deformities. Nevertheless, the classification system proposed by Ames et al. [19] is the currently most accepted one. It includes 5 deformity descriptors and 5 modifiers including: C2-C7 SVA, CBVA, T1S-CL, modified Japanese Orthopedic Association score and SRS-Schwab classification for thoracolumbar deformity. Although the intraand inter-observer reliability of this system has been reported to be satisfactory, the exact usefulness of this proposal is still unclear.

Table 1: Cervical Deformity Classification Ames et al. [20].

\begin{tabular}{|c|c|c|c|c|}
\hline \multicolumn{5}{|c|}{ Main Deformity Descriptor } \\
\hline \multicolumn{5}{|c|}{ C Apex of sagittal deformity in cervical spine } \\
\hline \multicolumn{5}{|c|}{ CT Apex of sagittal deformity at cervico thoracic junction } \\
\hline \multicolumn{5}{|c|}{ T Apex of sagittal deformity in thoracic spine } \\
\hline \multicolumn{5}{|c|}{ S Primary coronal deformity } \\
\hline \multicolumn{5}{|c|}{ CVJ Deformity located at cranio vertebral junction } \\
\hline \multicolumn{5}{|c|}{ Five Modifiers } \\
\hline C2-7 SVA & CBVA & CL minus T1S & Myelopathy (mJOA) & $\begin{array}{c}\text { SRS-Schwab } \\
\text { Classification }\end{array}$ \\
\hline $0:<4 \mathrm{~cm}$ & $0: 1^{\circ}$ to $10^{\circ}$ & $0:<15^{\circ}$ & $0: 18$ (none) & T, L, D or N (curve) \\
\hline $1: 4$ to $8 \mathrm{~cm}$ & 1: $-10^{\circ}$ to $0^{\circ}$ or $11^{\circ}$ to $25^{\circ}$ & 1: $15^{\circ}$ to $20^{\circ}$ & 1: $15-17$ (mild) & $0,+$, or $++($ PI-LL) \\
\hline \multirow[t]{2}{*}{$2:>8 \mathrm{~cm}$} & $2:<-10^{\circ}$ or $>25^{\circ}$ & $2:>20^{\circ}$ & 2: 12-14 (moderate) & $0,+$, or $++(\mathrm{PT})$ \\
\hline & & & $<12$ (severe) & $0,+$, or $++(\mathrm{C} 7-\mathrm{S} 1 \mathrm{SVA})$ \\
\hline
\end{tabular}

\section{Basic principles of cervical deformity correction}

The decision making in cervical deformity correction surgery is based on the following factors: neurological symptoms or deficit, flexibility of the deformity, location of deformity, presence of anterior or posterior ankylosis, concomitant thoracic or thoracolumbar deformity, and prior history of spinal surgery and general systemic status of patient. Overall, the goal of the surgery is to safely achieve an optimum cervical alignment based on the aforementioned cervical parameters. Nevertheless, the concepts are still evolving; and further research and experience can help us better understand the relative importance of each of these factors.

\section{References}

1. Blondel B, Schwab F, Bess S, Ames C, Mummaneni PV, et al. (2013) Posterior global malalignment after osteotomy for sagittal plane deformity: it happens and here is why. Spine 38(7): 394-401.
2. Smith JS, Shaffrey CI, Lafage V, Blondel B, Schwab F, et al. (2012) Spontaneous improvement of cervical alignment after correction of global sagittal balance following pedicle subtraction osteotomy. J Neurosurg Spine 17(4): 300-307.

3. Bailey DK (1952) The normal cervical spine in infants and children. Radiology 59(5): 712-719.

4. Fielding JW (1956) Cineradiography of the normal cervical spine. N Y State J Med 56(19): 2984-2986.

5. Weir DC (1975) Roentgenographic signs of cervical injury. Clin Orthop Relat Res 109: 9-17.

6. Tan LA, Straus DC, Traynelis VC (2015) Cervical interfacet spacers and maintenance of cervical lordosis. J Neurosurg Spine 22(5): 466-469.

7. Scheer JK, Tang JA, Smith JS, Acosta FL, Protopsaltis TS, et al. (2013) Cervical spine alignment, sagittal deformity, and clinical implications: a review. J Neurosurg Spine 19(2): 141-159.

8. Ames CP, Blondel B, Scheer JK, Schwab FJ, Le Huec JC, et al. (2013) Cervical radiographical alignment: comprehensive assessment 
techniques and potential importance in cervical myelopathy. Spine 38(22): S149-S160.

9. Tan LA, Riew KD, Traynelis VC (2017) Cervical Spine DeformityPart 1: Biomechanics, Radiographic Parameters, and Classification. Neurosurgery 81(2): 197-203.

10. Jeon S, Hyun SJ, Han S, Lee BH, Kim KJ, et al. (2018) Relationship Between Cervical Sagittal Alignment and Patient Outcomes After Anterior Cervical Fusion Surgery Involving 3 or More Levels. World Neurosurg 113: e548-e554.

11. Tang JA, Scheer JK, Smith JS, Deviren V, Bess S, et al. (2012) The impact of standing regional cervical sagittal alignment on outcomes in posterior cervical fusion surgery. Neurosurgery 71(3): 662-669.

12. Suk KS, Kim KT, Lee SH, Kim JM (2003) Significance of chin-brow vertical angle in correction of kyphotic deformity of ankylosing spondylitis patients. Spine 28(17): 2001-2005.

13. Song K, Su X, Zhang Y, Liu C, Tang X, et al. (2016) Optimal chin-brow vertical angle for sagittal visual fields in ankylosing spondylitis kyphosis. Eur Spine J 25(8): 2596-2604.

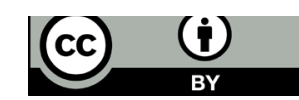

This work is licensed under Creative Commons Attribution 4.0 License DOI: 10.19080/OAJS.2018.09.555762
14. Lee SH, Kim KT, Seo EM, Suk KS, Kwack YH, et al. (2012) The influence of thoracic inlet alignment on the craniocervical sagittal balance in asymptomatic adults. J Spinal Disord Tech 25(2): E41-E47.

15. Kim HC, Jun HS, Kim JH, Ahn JH, Chang IB, et al. (2015) The effect of different pillow heights on the parameters of cervicothoracic spine segments. Korean J Spine 12(3): 135-138.

16. Oe S, Togawa D, Nakai K, Yamada T, Arima H, et al. (2015) The Influence of age and sex on cervical spinal alignment among volunteers aged over 50. Spine 40(19): 1487-1494.

17. Knott PT, Mardjetko SM, Techy F (2010) The use of the T1 sagittal angle in predicting overall sagittal balance of the spine. Spine J 10(11): 994998.

18. Hyun SJ, Kim KJ, Jahng TA, Kim HJ (2017) Clinical impact of T1 slope minus cervical lordosis following multilevel posterior cervical fusion surgery: A Minimum 2-Year Follow up data. Spine 42: 1859-1864.

19. Ames CP, Smith JS, Eastlack R, Blaskiewicz DJ, Shaffrey CI, et al. (2015) Reliability assessment of a novel cervical spine deformity classification system. J Neurosurg Spine 23(6): 673-683.

\section{Your next submission with Juniper Publishers will reach you the below assets}

- Quality Editorial service

- Swift Peer Review

- Reprints availability

- E-prints Service

- Manuscript Podcast for convenient understanding

- Global attainment for your research

- Manuscript accessibility in different formats

( Pdf, E-pub, Full Text, Audio)

- Unceasing customer service

Track the below URL for one-step submission https://juniperpublishers.com/online-submission.php 